\title{
Reseñas de exposiciones
}

Manuel Munive Maco

Instituto de Investigaciones Museológicas y Artisticas / Universidad Ricardo Palma

\section{SERGIO ZEVALLOS. MUSEO DE ARTE DE LIMA Y CENTRO CULTURAL DE ESPAÑA.}

Siempre he pensado que el alto nivel de la fotografia artística peruana, realizada entre 1983 y principios del siglo XXI, fue de alguna manera estimulado o condicionado por la crudeza de la fotografia periodística que durante aquellos mismos años registró, desde sus primeras planas, la prolífica matanza de peruanos originada por los grupos terroristas y la, también espeluznante, reacción de las fuerzas del Estado. La gravedad de las imágenes de prensa determinó, creemos, una ética respecto del oficio para fotógrafos como Javier Silva, Billy Hare o Roberto Huarcaya, por citar solamente a los más reconocidos, quienes eran conscientes de compartir el medio con reporteros que producían las imágenes más terribles y emblemáticas para la memoria visual de nuestro país. Quien escribe se siente formado por aquellas imágenes en blanco y negro que tenía que "desayunar" cada mañana en los kioscos de la esquina, ca-

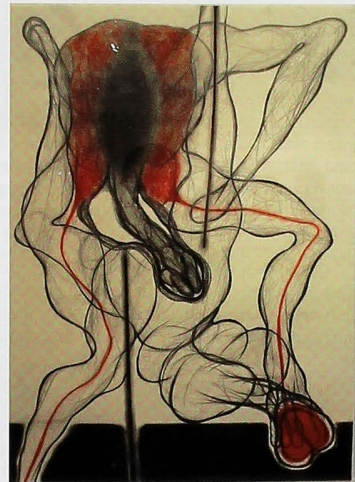

Sergio Zevallos. De la serie Sangre y Ceniza. Variaciones sobre la bandera. (1987). Grafito y témpera sobre papel. mino al colegio: cabezas cercenadas, amasijos de cadáveres, autopsias masivas, cuerpos siempre incompletos por obra de los "coches bomba" senderistas.

Estas circunstancias y el que me desempeñara como teatrista en Lima entre los años 1990 y 1995 me inmunizaron -creo que excesivamente- ante la fotografia que documenta performances y "acciones" de artistas visuales peruanos o extranjeros. Los espectáculos teatrales también requerian de fotografias impresas en papel para su difusión en los medios de prensa y era inevitable compararlas, por ejemplo, con las imágenes que conocía del grupo Chaclacayo, trío de artistas cuyo periplo se había mitificado tanto como todo aquello que sufre la bendición de la censura y que disfruta de su "ocultismo". (Sé de buena fuente que solamente invitaban a críticos y "entendidos" a su casa-taller del distrito que dio nombre al grupo). A principios de los noventa había llegado a mis manos el afiche/catálogo de su exposición censurada en el Museo de Arte de Lima y me sirvió para reflexionar acerca de los artistas cuya imagen personal se impone a la de sus realizaciones artísticas, tal como suele suceder con los músicos y los actores ya que antes que "obras" encontraba allí sus retratos y las fotografías de las "acciones" de uno de sus miembros, Sergio Zevallos.

"Un cuerpo ambulante. Sergio Zevallos en el Grupo Chaclacayo (1982-1994)" es la exposición que nos incitó a redactar estas líneas. Esta exposición es, en verdad, un apéndice 
de la exposición mayor titulada "Perder la forma humana. Una imagen sísmica de los años ochenta en América Latina" realizada por curadores jóvenes sudamericanos que rastrearon, seleccionaron y rescataron materiales documentales -fotografias, ediciones, video- y en mínima medida "obras" resultantes de las diferentes experiencias contraculturales en la región surgidas primordialmente como una reacción a las coyunturas políticas represivas de sus respectivos países. Miguel López, uno de ellos, aprovechó para preparar "Un cuerpo ambulante", una exposición realizada en dos "capítulos": uno en la sala pequeña del Museo de Arte de Lima y otro en el Centro Cultural de España. Los trabajos de Zevallos presentados en este último espacio son los que nos interesa reseñar ahora por la claridad con la que nos permite contrastar la solidez de una "obra" realizada versus el "documento".

En la sala del C. C. de España encontramos dos conjuntos: fotografías a color y obras en papel. La primera, una serie bastante dilatada de las performances o acciones que caracterizaron al aporte de Zevallos dentro del grupo Chaclacayo y donde el artista hace gala de un narcisismo oscuro al encarnar una versión siniestra y luctuosa de Santa Rosa de Lima, personaje colonial ciertamente esquizofrénico: remarcando monocordemente su genitalidad masculina Zevallos manifestaba así la contrariedad de quien se siente atrapado en una anatomía equívoca. Y es la tragedia de esa contrariedad la que a nuestro modo de ver anima esas acciones escrupulosamente registradas. No creemos que se trate, como afirma el curador, de una "obra" en la que repercute el contexto de muerte durante la violencia de los años ochenta en el Perú. Pero esto que afirmo, sin duda, es discutible.

Lo que es indudable es la ostensible superioridad de la obra en papel de Zevallos con respecto a ese juego de fotografias que ya esperábamos ver. En efecto: en la sala de Santa Beatriz se exhiben dos conjuntos de dibujos y técnicas mixtas realizados con un rigor y una inteligencia que sepulta el histrionismo de las fotografias pues aquellos dibujos dicen mejor -connotando- lo que las fotografías balbucean - denotando- acerca de la colisión entre la "crisis" del "yo" del artista y la realidad que le tocó vivir. Esto es particularmente logrado en la serie titulada "Sangre y Ceniza. Variaciones sobre la bandera" del año 1987, en la que empezando con la representación "filodurista" de nuestra bandera deriva pronto en representaciones figurativas trazadas en un espacio gráfico opresivo y claustrofóbico en el que un cuerpo masculino -el "yo corporal" del artista- sufre una serie de agresiones en pos del placer y el dolor. Es en estos dibujos donde se equipara la anatomía humana con la del animal del sacrificio, la agonía y el orgasmo, la penetración sexual y el apuñalamiento o el nacimiento y la excreción. El cuerpo desenmascarado a partir de su genitalidad perversa. Y el rojo desvaído de nuestra bandera como fluido sanguíneo que da una coloración marchita.

Notable como la anterior es la serie titulada "Símbolos, huellas de un crimen" realizados entre 1985 y 1986, en grafito sobre papel. Más allá de la influencia baconiana reconocemos también allí el eco de una estética impartida en la Universidad Católica y afín a los lenguajes de otros artistas de la generación de Zevallos -y probablemente condiscípulos- como Johanna Hamann, Jorge Castilla-Bambarén y Eduardo Tokeshi'

Después de la muerte fotografiada e impresa en los diarios limeños las fotografías de las performances donde Zevallos juguetea con la muerte no llegan a ser más que un disfuerzo egolátrico. Por suerte, la exposición organizada por Miguel López nos permitió acceder a una obra valiosa que ignorábamos y que corrige nuestra primera impresión acerca de las capacidades intelectuales de su autor. Lamentablemente este segmento es el que menos difusión tiene y eso lo demuestra que haya sido mostrado fuera de la exposición del

1 Notable es la serie de 1982, titulada "Estampas" en las que el artista interviene un conjunto de alrededor de doce copias fotostáticas de la imagen devocional de Santa Rosa de Lima mediante el carbón, tiza y el collage pero que forma parte de su participación en el Museo de Arte de Lima. 
museo. ¿Será que ahora los curadores jóvenes prefieren censurar aquella obra que no fue censurada porque puede parecer menos sexy conceptual y epocalmente?

\section{GERARDO CHÁVEZ. GALERÍA ENLACE ARTE CONTEMPORÁNEO.}

Gerardo Chávez (Trujillo, 1937) reconoce abiertamente la influencia de dos genios de la pintura latinoamericana del siglo XX en su obra temprana: la del chileno Roberto Matta y la del cubano Wifredo Lam, a quienes conoció a principios de los años sesenta; al primero en Roma y al segundo en París. $\mathrm{Al}$ parecer ambos pintores aprecian "a primera vista" los cuadros del joven peruano que había quemado las naves y optado por erigir una Obra en Europa, trabajando y exponiendo en Florencia, Roma, Ámsterdam y Bruselas, hasta re-

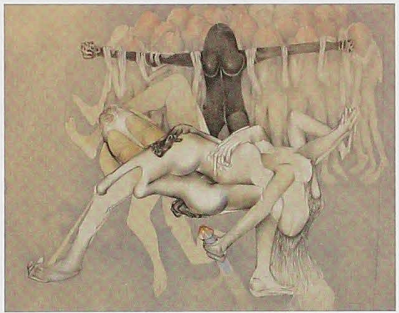

Gerardo Chávez. Idole possédée (1978). Pastel graso sobre tela. $114 \times 146 \mathrm{~cm}$. calar en París, ciudad donde permaneció varias décadas y a donde regresa de cuando en cuando.

Su tendencia natural por la figuración -reforzada por el hecho de construir su universo plástico a partir de un grácil y sólido dibujo- lo van aproximando estilísticamente hacia el pintor cubano de quien incorpora elementos anatómicos notorios pero prodigiosamente transfigurados por un erotismo extremo en el que el coito ocupa el lugar de una ceremonia convulsa a la que asiste una multitud de espectadores y en la que participan incluso algunos cuadrúpedos acezantes. Pero un descubrimiento técnico hace que su trabajo de estos años sea un aporte particularmente original: el manejo del pastel graso sobre el lienzo con el que plasma una imaginería etérea en la que los trazos parecen difuminarse sobre la tonalidad natural del lino crudo.

Chávez, que renueva sus ciclos temáticos conjuntamente con las técnicas pictóricas empleadas -tal como lo demuestra su uso inicial del óleo, entre 1960 y 1970, o las tierras de color sobre yute, entre 1993 y 2006- se sirvió exclusivamente del pastel graso para ejecutar sus obras entre los años 1971 y 1982. El éxito de su comercialización en Europa nos privó del placer de verlos expuestos con mayor frecuencia en el Perú. Afortunadamente la galería Enlace Arte Contemporáneo, organizó una notable exhibición a principios de este año, reuniendo -tras una pesquisa de varios años- un conjunto valioso de esos "pasteles grasos sobre tela", que tanto los estudiantes de arte, los críticos y los diletantes ansiábamos ver.

\section{EDUARDO VILLANES. LA GALERÍA.}

La plástica del pasado precolombino asoma de cuando en cuando en la obra de algunos notables artistas visuales peruanos. Pero lo singular de este

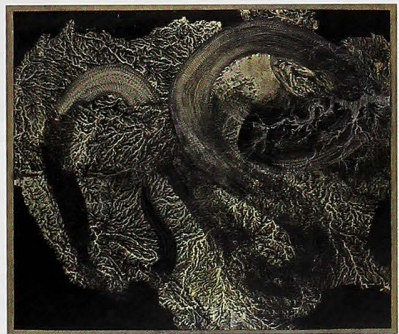

Eduardo Villanes B. Tributarios del Amazonas (2012) Óleo y láminas de plata sobre lino. 140 × $160 \mathrm{~cm}$. 
fenómeno es que éstos no parten necesariamente de los acervos iconográficos heredados sino que prefieren apoyarse en la materialidad que les da cuerpo y soporte: encontramos, por ejemplo, una esculturà contemporánea basada en la indagación del bloque pétreo de la arquitectura inca (Mutal y Prager); una pintura de caballete que utiliza la arena del desierto como pigmento (Eielson y Wiesse) así como instalaciones erigidas con adobes cónicos semejantes a los usados en la construcción de pirámides durante el siglo $V$ (Vainstein). Pareciera que ante la carencia de una escritura que explique los misterios de ese pasado remoto estos creadores contemporáneos recurren a lo más tangible -la piedra, el textil, el barro- para tentar un desciframiento. Eduardo Villanes Baricheva (Moscú, 1967) forma parte de este selecto grupo.

Villanes elabora una pintura sumamente peculiar: realiza incisiones que replican los "diseños" de la epidermis de la serpiente o el jaguar sobre la superficie fresca del óleo negro, el único "color" que emplea hace quince años. Las delgadas marcas con las que "talla" ambos animales evocan las incisiones que sobre el granito labraron los artistas de Chavín, una sociedad que existió alrededor del año 1500 a. C. en los andes peruanos y para la que, coincidentemente, el ofidio y el felino, junto a la falcónida, conformaban la tríada sagrada sobre la cual articularon su cosmogonía.

En la pieza que ilustra este artículo vemos a la Yakumama o "Madre del agua", la gran serpiente mítica de la selva peruana, emergiendo y zambulléndose sobre un territorio "labrado" por la miríada de afluentes de la cuenca hidrográfica del Amazonas que Villanes ha "transcrito" sobre el lienzo previamente mediante el auxilio de la serigrafía.

Una pintura en técnica mixta que es una certera explicación cosmogónica, una cartografía poética -ajena a los linderos geopolíticos-y una advertencia ecológica sobre la fragilidad de la Amazonía.

\section{TRADICIONES SIN TIEMPO. SALA KRÜGER DEL ICPNA}

Desde el 2003 el Instituto Cultural Peruano Norteamericano y la Universidad Ricardo Palma se unen para para producir una exposición anual dedicada exclusivamente a la plástica tradicional y popular del Perú. El "cajón sanmarkos", el mate burilado, la cerámica vidriada, la textilería o la platería popular, entre otras "técnicas", así como enfoques regionales -Ayacucho o Cusco- o conceptuales como la supervivencia del arte virreinal en el arte popular, por ejemplo, sirvieron como ejes articuladores de

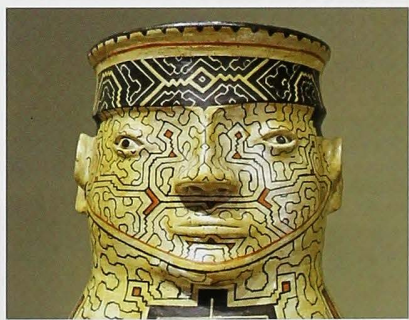

Joni Chomo. Cerámica escultórica y policromada shipibo-conibo. Pormenor. las piezas cuya selección recayó, en cada ocasión, en manos de curadores casi siempre historiadores del arte o antropólogos.

Para la exposición actual, "¿Arte popular? Tradiciones sin tiempo", se convocó como curadores a Mary Solari, Jaime Liébana y John Alfredo Davis, tres de los coleccionistas más importantes de nuestro medio quienes desde hace más de diez años integran el Comité de Arte Popular en el que, junto a Fernando Torres por parte del ICPNA y Alfonso Castrillón por la U. Ricardo Palma, se define el concepto de cada muestra a realizarse indefectiblemente en la sala "Germán Krüiger". 
Y la participación de los mencionados coleccionistas como curadores de la exposición se hace patente en tanto encontramos representadas allí las preferencias estéticas y criterios conceptuales que aplicaron en la conformación de sus propios acervos.

"[Esta exposición] propone lecturas alternas, priorizando los procesos en que se forma y desenvuelven los artífices intelectuales y materiales de las piezas; los propósitos que motivan la producción, hábitos de consumo y distribución de los objetos así como el desarrollo de 'nuevos gustos' de los peruanos. El recorrido de la exposición pretende hacer visibles las narrativas estéticas de origen étnico, rural y urbano, cada una de las cuales ostentan sistemas simbólicos y formas de expresión particulares que responden a entornos culturales, agentes, espacios de circulación, mercados y otros fenómenos propios de un país complejo y diverso"2.

En el caso de las tres cruces cerámicas de Mamerto Sánchez, mostradas una al lado de la otra para ilustrar las profundas variaciones que un elemento puede experimentar en manos de un mismo autor, vemos como el motivo originalmente cristiano se independiza como un objeto plástico que integra lo escultórico y pictórico.

El "Joni Chomo", también un espécimen de arcilla modelada y cocida, a diferencia de la pieza del artista andino Sánchez, respeta en gran parte la tipología tradicional, ancestral y anónima que la creó, aun cuando ha sido elaborado hace menos de diez años por un artista amazónico, cuyo origen es inconfundible en los diseños geométricos que recorren todo el cuerpo del varón representado, tal como sucede en la vida real pues esta linealidad exquisita además de signar las vasijas, se traza sobre los tejidos que conforman la vestimenta y sobre la piel.

Si bien las máscaras son objetos equivalentes a los "vestigios" de expresiones dancísticas y musicales, sus variopintos materiales y sus ingeniosas soluciones plásticas son también un testimonio de la complejidad y diversidad cultural de nuestro país tal como lo ilustra la máscara de hojalata policromada perteneciente a uno de los personajes de la danza de los Negritos, una de las más difundidas a lo largo de nuestra geografía.

La "pechera" que ostenta el escudo nacional bordado con hilos de colores aun cuando no es una sofisticada pieza textil y es más bien "naif", expresa como pocas una profunda identidad nacional sintetizada en el modo en que su autor plasmó cada uno de los símbolos de la Patria.

La pintura popular que representa esos felinos rugientes - ijaguares o tigres de Bengala?parece un revival del milenario culto andino al otorongo amazónico, en su función de amedrentadores guardianes.

Y las botellas, garrafas y vasos de vidrio soplados son también ejemplares de esa "apropiación" que motivó en gran medida la producción de una plástica rural que adoptaba la forma de los objetos suntuarios adquiridos por las elites provincianas mediante materiales más modestos y accesibles. Estas bellas y sencillas piezas utilitarias nos exhortan también a protegerlas de la extinción a las que parecen estar condenadas.

Debemos terminar precisando que la muestra está dedicada al extraordinario retablista e imaginero Jesús Urbano Rojas (1925-2014) recientemente fallecido, figura imprescindible dentro de la historia del arte popular peruano. Leer su testimonio en el libro editado por Pablo Macera a partir de las largas conversaciones sostenidas con él -Santero y caminante (1992)- puede ser una efectiva manera de recordarlo y una perfecta manera de iniciarnos en la comprensión de la cultura de nuestros artistas andinos.

2 Extracto del texto de presentación publicado en el trifolio que se distribuyó en la sala de exposiciones. 


\section{PATRICK TSCHUDI. GALERÍA LUCÍA DE LA PUENTE}

Fue a partir de los años treinta del siglo pasado que se diseña y difunde la convención gráfica que representa al individuo moderno mediante aquella silueta negra y concisa que rige hasta hoy con algunas variantes. Muchos de esos diseños o "iconos" regularon nuestro "comportamiento social", velando por nuestra seguridad y confort, como preceptores silenciosos y sucintos en medio de la vorágine de las grandes urbes.

El trabajo reciente de Patrick Tschudi (Lima, 1973) involucra precisamente a aquellos iconos antropomorfos con los que nos hemos familiarizado a lo largo del tiempo al punto de aceptarlos como las versiones sumarias de nosotros.

Tschudi explora las posibilidades expresivas de esos "sujetos" gráficos al sacarlos de su

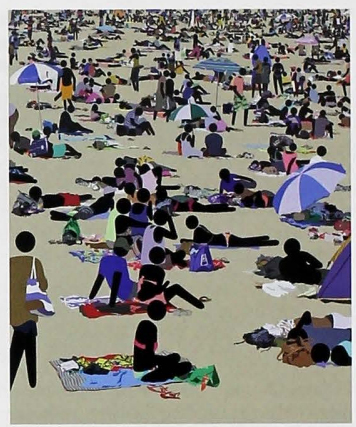

Patrick Tschudi. Where time stands still (2013). Dibujo vectorial, impresión lambda.

aséptico, silencioso y monocromo ámbito "comunicativo" y llevarlos a otro, también bidimensional, en el que fungen de protagonistas. Cada uno de estos cuadros narrativos desarrollados en "locaciones" diversas -la playa, el parque, el acantilado así como el bar o la gasolinera-nos otorgan, como en una "postal" -y en una gama pletórica y plana-apacibles y distantes fracciones del mundo.

Desde su primera individual en Lima, hace dos años, la propuesta de Tschudi se ha constituido en un paradigma local de la pertinencia de los "nuevos medios": las imágenes que nos ofrece no pueden -o no deben- ejecutarse mediante los procedimientos pictóricos tradicionales y requieren, por el contrario, de una manipulación digital - "indirecta" y neutral- para "transcribir" cada uno de los elementos contenidos en las fotografias que ha rescatado del caudal infinito y anónimo de la Internet y que son el punto de partida de su trabajo. Anulando - ¿y censurando?- la fisonomía y todo aquello que revele la identidad de los individuos que las habitan, el artista crea regimientos de sujetos indistintos forjados así por la rutina cotidiana entre las cuatro paredes de sus respectivas y atestadas ciudades.

Con la serie de obras de "Postales póstumas", su segunda muestra personal en Lima, Patrick Tschudi articula una visión panorámica de la globalizada humanidad contemporánea: no solo remarca nuestra condición de "especie" al representarnos "idénticos" en el esparcimiento y el tedio sino que nos revela uniformizados por el consumismo. En un futuro no muy lejano cada una de estas "postales" podrá tomarse como un documento antropológico de la gozosa transformación del hombre en un simulacro de sí mismo. 